\title{
含酪氨酸三肽自由基离子的形成、异构和解离 反应机理研究
}

\author{
路时芳, 曹洁*，贾贺园，孙炼琪，陈世稆* \\ 北京理工大学化学与化工学院, 原子分子簇科学教育部重点实验室, 北京 100081 \\ *通讯作者, E-mail: jcao@bit.edu.cn; shlchen@bit.edu.cn \\ 收稿日期：2020-05-20; 接受日期：2020-06-22; 网络版发表日期：2020-08-13 \\ 国家自然科学基金(编号: 21371025)资助项目
}

摘要本文使用铜-配体-三肽组成的三元复合物 $[\mathrm{Cu}(\mathrm{L}) \mathrm{Peptide}]^{2+}$ (配体 $\mathrm{L}=4^{\prime}-$ 氯-2,2': $6^{\prime}, 2^{\prime \prime}$-三联吡啶, 缩写 $4 \mathrm{Cl}$ tpy; Peptide=丙氨酰-酪氨酰-甘氨酸( AYG)或甘氨酰-酪氨酰-甘氨酸 $(G Y G)$ ) 通过碰撞诱导解离(collision-induced dissociation, CID)的方法, 成功制备了 $\mathrm{AYG}$ 和 $\mathrm{GYG}$ 两个系列自由基离子([AYG $]^{\bullet+},\left[\mathrm{AYG}^{\bullet}\right]^{+} ;[\mathrm{GYG}]^{\bullet+},\left[\mathrm{G}^{\bullet} \mathrm{YG}^{+}\right]^{+}$和 $\left[\mathrm{GYG}^{\circ}\right]^{+}$). 通过对比 $\mathrm{AYG}$ 不同位点自由基离子的 $\mathrm{CID}$ 谱图以及对比 $\mathrm{AYG}$ 和 $\mathrm{GYG}$ 两个系列自由基离子的 CID谱图, 结合密度泛函理论(density functional theory, DFT)计算, 阐明AYG自由基离子的气相异构/解离反应机理, 并解释 了 $\mathrm{AYG}$ 和 $\mathrm{GYG}$ 自由基离子不同解离行为的内在原因. 研究表明, (1) $[\mathrm{AYG}]^{\circ+}$ 和 $\left[\mathrm{AYG}{ }^{\circ}\right]^{+}$的解离路径基本相同, 二者 的主要裂解产物均为 $\left[\mathrm{x}_{2}+\mathrm{H}\right]^{\bullet+}$ 离子, 说明二者在解离之前已完全异构. (2) $\left[\mathrm{A}^{\bullet} \mathrm{YG}\right]^{+}$和 $\left[\mathrm{G}^{\circ} \mathrm{YG}\right]^{+}$的解离路径相同, 二 者均断裂酰胺 $\mathrm{C}-\mathrm{N}$ 键, 产生 $\left[\mathrm{b}_{2}-\mathrm{H}\right]^{\bullet+}$ 碎片离子, 说明 $\left[\mathrm{A}^{\bullet} \mathrm{YG}\right]^{+}$不能异构为 $[\mathrm{AYG}]^{\bullet+}$ 和 $\left[\mathrm{AYG}^{\bullet}\right]^{+}$. (3) DFT计算给出了 $\mathrm{AYG}$ 三个自由基离子的稳定性顺序 $\left(\left[\mathrm{A}^{\bullet} \mathrm{YG}^{+}>\left[\mathrm{AYG}^{\bullet}\right]^{+}>[\mathrm{AYG}]^{\bullet+}\right)\right.$ 和它们的异构/解离能垒. $\left[\mathrm{AYG}^{*}\right]^{+} \rightarrow[\mathrm{AYG}]^{\bullet+}$ 的异 构能垒 $(47.4 \mathrm{kcal} / \mathrm{mol})$ 低于 $\left[\mathrm{AYG}^{\circ}\right]^{+}$的解离能垒 $(72.7 \mathrm{kcal} / \mathrm{mol})$, 但高于 $[\mathrm{AYG}]^{\circ+}$ 的解离能垒 $(44.3 \mathrm{kcal} / \mathrm{mol})$, 由此得 到 $\left[\mathrm{AYG}^{\circ}\right]^{+}$的气相裂解反应机理为 $\left[\mathrm{AYG}^{\circ}\right]^{+} \rightarrow[\mathrm{AYG}]^{\bullet+}$ 的异构过程，再经历 $[\mathrm{AYG}]^{\bullet+} \rightarrow\left[\mathrm{x}_{2}+\mathrm{H}\right]^{\bullet+}$ 的解离反应，断裂

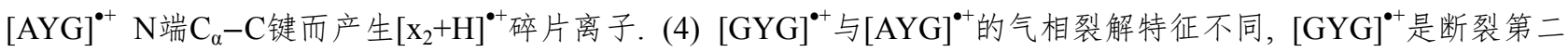
个 $\mathrm{N}-\mathrm{C}_{\alpha}$ 键 (从 $\mathrm{N}$ 端氨基酸残基数起) 产生 $\left[\mathrm{Z}_{2}-\mathrm{H}\right]^{\bullet+}$ 碎片离子.

关键词电喷雾串联质谱(ESI-MS/MS), 密度泛函理论计算, 三肽自由基离子, 气相异构和解离反应

\section{1 引言}

蛋白质是多肽链经过螺旋和折叠形成的具有一定 功能的生物大分子, 它是生命活动的承担者, 研究蛋白 质的组成、结构和功能对于深刻理解重要的生理病理 现象和制定正确的医疗策略具有重要的意义. 多肽自
由基离子在生物体系中参与了许多重要的生命活动, 是牛海绵状脑炎和阿尔兹海默症等疾病的关键中间 体 $^{[1 \sim 4]}$, 其中的甘氨酸自由基离子和 $\alpha$ 自由基离子(自由 基在氨基酸的 $\mathrm{C}_{\alpha}$ 上) 还分别参与III类核糖核苷酸还原 酶(RNR)的催化过程和许多氧化反应 ${ }^{[5,6]}$. 与质子化的 多肽离子 $\left([\mathrm{M}+\mathrm{nH}]^{n+}\right)$ 相比，多肽自由基离子 $\left(\mathrm{M}^{\bullet+}\right)$ 同时

引用格式: Lu S, Cao J, Jia H, Sun S, Chen S. Formation, isomerization, and dissociation of tyrosine-containing tripeptide radical cations. Sci Sin Chim, 2020, 50: 1177-1186, doi: 10.1360/SSC-2020-0080 
具有电荷和自由基两个反应中心, 反应活性更高, 既可 以发生电荷诱导的解离反应，又可以发生自由基诱导 的解离反应，可以产生更加丰富的碎片离子，如电荷 诱导的、断裂多肽骨架上酰胺 $\mathrm{C}-\mathrm{N}$ 键产生 $\mathrm{b} / \mathrm{y}$ 系列离 子, 还有自由基诱导的、断裂多肽骨架上 $\mathrm{N}-\mathrm{C}_{\alpha}$ 键或 $\mathrm{C}_{\alpha}$ $-\mathrm{C}$ 键产生 $\mathrm{c} / \mathrm{z}$ 或 $\mathrm{a} / \mathrm{x}$ 离子, 或者断裂侧链的 $\mathrm{C}_{\alpha}-\mathrm{C}_{\beta}$ 或 $\mathrm{C}_{\beta}$ $-C_{\gamma}$ 键丢失全部或部分侧链等(图1 $)^{[7,8]}$, 对确定蛋白质 的结构更有利. 此外, Peptide ${ }^{\circ+}$ 的解离过程涉及质子转 移、电子转移、重排和异构等复杂过程 ${ }^{[9 \sim 12]}$, 研究 Peptide ${ }^{\bullet+}$ 的气相裂解行为对设计具有特定功能的多肽 分子具有重要意义.

目前，产生多肽自由基离子的方法主要有电子轰 击电离(electron impact ionization, EI) ${ }^{[13]}$ 、激光解吸/ 多光子电离(laser desorption/multiphoton ionization) ${ }^{[14]}$ 、电子捕获解离(electron capture dissociation, $\mathrm{ECD})^{[15 \sim 17]}$ 、电子转移解离 (electron transfer dissociation, ETD $)^{[18-20]}$ 和金属-配体-多肽三元复合物的 $\mathrm{CID}^{[21]}$ 以及修饰了化学基团 ${ }^{[22 \sim 26]}$ 或自由基引发剂 ${ }^{[27,28]}$ 多肽的 CID等，其中以金属-配体-多肽三元复合物的CID方法 最为常见. 这种方法一般可以得到两种类型的自由基 离子: 荷基同位离子(自由基和电荷在同一个位置, 如 $\pi$ 和 $\mathrm{S}$ 自由基离子)和荷基异位离子(自由基和电荷在不 同原子上，如 $\alpha$ 自由基离子). 通过金属-配体-多肽三元 复合物的CID反应, 首先得到荷基同位离子, 该离子可 进一步发生丢失侧链的碎裂反应, 断裂侧链 $\mathrm{C}_{\alpha}-\mathrm{C}_{\beta}$ 键 从而产生 $\alpha$ 自由基离子，如多肽中的色氨酸 $(\mathrm{W})$ 、酪氨 酸 $(\mathrm{Y})$ 和甲硫氨酸 $(\mathrm{M})$ 都可丢失其全部侧链产生 $\alpha$ 自由 基离子 ${ }^{[7,9,10,29,30]}$. 图2是以 $\mathrm{AYG}$ 三肽为例说明 $\left[\mathrm{AYG}^{\circ}\right]^{+}$的 形成过程. $\mathrm{Chu}$ 等 ${ }^{[10]}$ 曾通过 $[\mathrm{WGY}]^{++}$和 $[\mathrm{YGW}]^{\bullet+}$ 分别得 到了 $\left[\mathrm{G}^{\bullet} \mathrm{GY}\right]^{+}$和 $\left[\mathrm{G}^{\bullet} \mathrm{GW}\right]^{+}$; Hopkinson等 ${ }^{[30]}$ 曾探讨过 $[\mathrm{MG}]^{-+}$和 $[\mathrm{GM}]^{\bullet+}$ 的裂解机理, 成功地通过 $[\mathrm{GM}]^{\bullet+}$ 得到 了 $\left[\mathrm{GG}^{\bullet}\right]^{+}$, 但是他们研究的这两种自由基离子 $\left([\mathrm{MG}]^{\bullet+}\right.$ 和 $\left.[\mathrm{GM}]^{\bullet+}\right)$ 的电荷和自由基都在 $\mathrm{S}$ 原子上, 目前 还没有人探讨过当酪氨酸 $(\mathrm{Y})$ 和甲硫氨酸 $(\mathrm{M})$ 同时存在 且 $M$ 在 $C$ 端、 $Y$ 在中间(电荷和自由基都在 $Y$ 上)时，多 肽自由基离子是否能产生 $\mathrm{C}$ 端 $\alpha$ 自由基离子.

近年来, 多肽自由基离子的工作主要集中在其解 离机理研究. $\mathrm{Siu}$ 等 ${ }^{[31]}$ 报道了三肽自由基离子 $\left[\mathrm{G}^{\bullet} \mathrm{GG}\right]^{+} 、\left[\mathrm{GG}^{\bullet} \mathrm{G}^{+}\right.$和 $\left[\mathrm{GGG}^{\bullet}\right]^{+}$, 探讨了自由基位点对 解离的影响, 他们还探讨过 $\mathrm{N}-\mathrm{C}_{\alpha}$ 键断裂产生 $\mathrm{c} / \mathrm{z}$ 离子 的竞争反应 ${ }^{[32]}$; Chu等研究了 $\mathrm{N}$ 端氨基酸的碱性对三

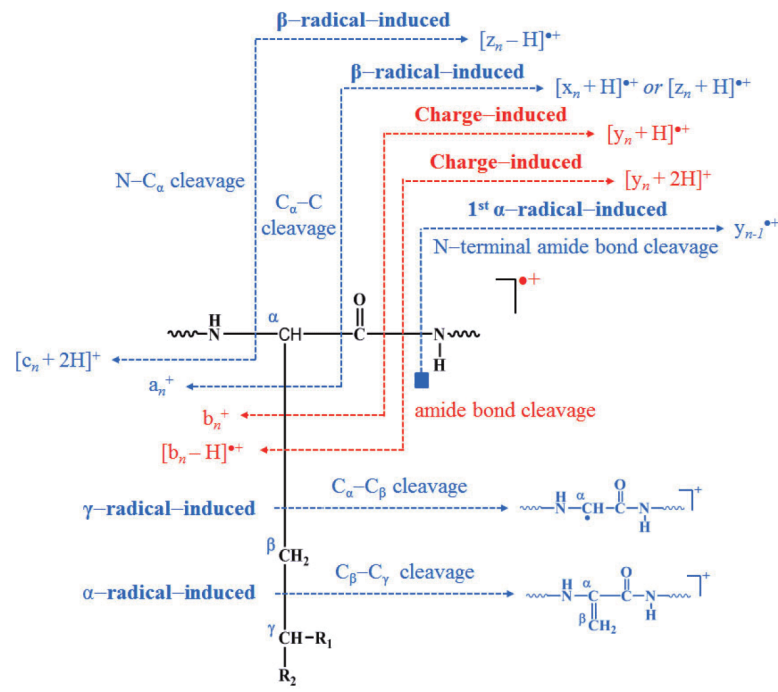

图 1 多肽自由基离子电荷诱导和自由基诱导的气相裂解 反应(网络版彩图)

Figure 1 Charge- and radical-induced fragmentations of peptide radical cations (color online).

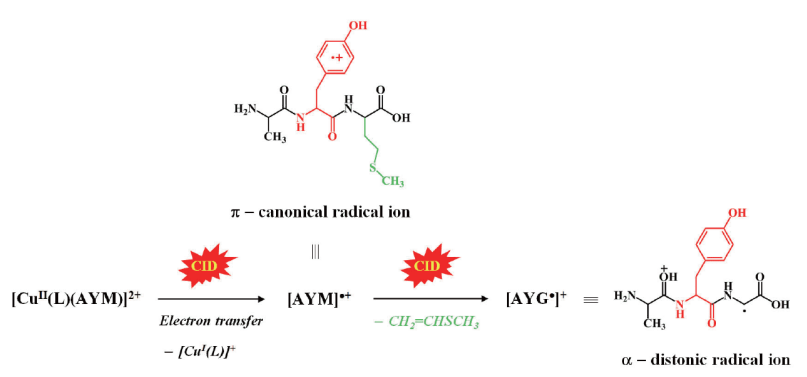

图 $2 \pi$ 和 $\alpha$ 多肽自由基离子的形成机制(网络版彩图)

Figure 2 Formation mechanisms of $\pi$ and $\alpha$ radical cations of peptides (color online).

肽自由基离子 $\left[\mathrm{RYG}^{\bullet+} 、[\mathrm{KYG}]^{\bullet+} 、[\mathrm{NYG}]^{\bullet+}\right.$ 和 $[\mathrm{AYG}]^{\bullet+}$ 的裂解行为的影响, 还研究了二肽自由基离子 $[\mathrm{AY}]^{\circ+}$ 的 $\mathrm{N}$ 端 $\mathrm{C}_{\alpha}-\mathrm{C}^{\text {键的断裂机理 }}{ }^{[33]}$. 但是, $\left[\mathrm{AYG}^{\circ}\right]^{+}$和 $[\mathrm{AYG}]^{\circ+}$ 的异构/解离的竞争反应以及 $\mathrm{AYG}$ 系列自由基 离子 $\left([\mathrm{AYG}]^{\bullet+} 、\left[\mathrm{~A}^{\bullet} \mathrm{YG}\right]^{+}\right.$和 $\left.\left[\mathrm{AYG}^{\bullet}\right]^{+}\right)$和 $\mathrm{GYG}$ 系列自由 基离子 $\left([\mathrm{GYG}]^{\bullet+} 、\left[\mathrm{G}^{\bullet} \mathrm{YG}\right]^{+}\right.$和 $\left.\left[\mathrm{GYG}^{\circ}\right]^{+}\right)$气相解离反应 的对比研究尚未见报道, 研究以上内容对深入理解具 有不同自由基位点三肽自由基离子的解离特点和解离 机理具有重要的意义.

本工作采用电喷雾串联质谱(ESI-MS/MS)方法并 结合密度泛函理论计算, 研究了 $\left[\mathrm{AYG}^{\bullet}\right]^{+}$前驱体 $\left([\mathrm{AYM}]^{\bullet+}\right.$ 和 $\left.[\mathrm{AYW}]^{\bullet+}\right)$ 的气相反应机理; 探索三种具有 不同自由基位点的 $\mathrm{AYG}$ 自由基离子 $\left([\mathrm{AYG}]^{\bullet+}\right.$ 、 
$\left[\mathrm{A}^{\bullet} \mathrm{YG}\right]^{+}$和 $\left.\left[\mathrm{AYG}^{\bullet}\right]^{+}\right)$的气相稳定性及其异构/解离的竞 争反应过程; 研究 $[\mathrm{AYG}]^{\bullet+}$ 和 $[\mathrm{GYG}]^{\bullet+}$ 的气相解离行为 差异, 以深入探究自由基位点和多肽中氨基酸种类对 多肽自由基离子异构/解离反应的影响, 并深入理解生 物体系中自由基介导的复杂反应历程.

\section{2 实验部分}

\section{1 试剂与仪器}

Wang树脂(1.2 mmol $/ \mathrm{g}, 100 \sim 200 \mathrm{mesh}, 1 \%$ DVB) 购自天津南开和成技术有限公司, Fmoc-L-色氨酸 (Boc)、Fmoc-L-蛋氨酸、二氯甲烷、二异丙基碳二亚 胺、4-二甲氨基吡啶、三异丙基硅烷、甲基叔丁基 醚、甲醇和高氯酸铜均购自上海麦克林生化科技有限 公司, $N$-芴甲氧羰基-甘氨酸、Fmoc-O-叔丁基-L-酪氨 酸、Fmoc-L-丙氨酸、1-羟基苯并三唑、三氟乙酸和 $4^{\prime}$-氯- $2,2^{\prime}: 6^{\prime}, 2^{\prime \prime}$ 二三联吡啶均购自萨恩化学技术(上海) 有限公司, $N, N$-二甲基甲酰胺购自北京化工厂, 二乙胺 购自北京伊诺凯科技有限公司，乙醇购自上海阿拉丁 生化科技有限公司.

使用的仪器是Bruker离子阱质谱仪(Amazon Speed Dual Funnel, 德国)配有电喷雾离子源(ESI)及 Data Analysis 5.1数据处理系统.

\section{2 实验方法}

\subsection{1 $\mathrm{Cu}(4 \mathrm{Cl}-\mathrm{tpy})\left(\mathrm{ClO}_{4}\right)_{2}$ 的合成}

$\mathrm{Cu}\left(\mathrm{ClO}_{4}\right)_{2}$ 和 $4^{\prime}$-氯- $2,2^{\prime}: 6^{\prime}, 2^{\prime \prime}$-三联吡啶(4Cl-tpy) 分 别用水和乙醇溶解后, 在 $130^{\circ} \mathrm{C}$ 加热的情况下以摩尔比 1.5: 1混合反应, 用冷的 $\mathrm{CH}_{3} \mathrm{CH}_{2} \mathrm{OH}: \mathrm{H}_{2} \mathrm{O} \quad(1: 1)$ 重结晶 2 次后, 得到纯的 $\mathrm{Cu}\left(4 \mathrm{Cl}\right.$-tpy) $\left(\mathrm{ClO}_{4}\right)_{2}$. 此合成参考文 献 ${ }^{[34]}$ 中的方法, 用 $\mathrm{Cu}\left(\mathrm{ClO}_{4}\right)_{2}$ 代替 $\mathrm{Cu}\left(\mathrm{NO}_{2}\right)_{2}, 4 \mathrm{Cl}$-tpy代 替三联吡啶(terpy), $\mathrm{Cu}\left(\mathrm{ClO}_{4}\right)_{2}$ 和 $4 \mathrm{Cl}$-tpy反应时的摩尔 比由 $1: 1$ 改为 $1.5: 1$.

\subsection{2 三肽的合成}

参照参考文献 ${ }^{[35]}$, 采用Fmoc固相合成法合成三 肽, 脱保护试剂用二乙胺代替哌啶, 反应流程图参见 图S1(网络版补充材料).

\subsection{3 $\left[\mathrm{Cu}(4 \mathrm{Cl}-\mathrm{tpy})\right.$ Peptide] $\left(\mathrm{ClO}_{4}\right)_{2}$ 溶液的制备}

称取 $1 \mathrm{mg}$ 三肽, 用 $1 \mathrm{~mL}$ 水溶解; 再称取 $1 \mathrm{mg} \mathrm{Cu}$
(4Cl-tpy) $\left(\mathrm{ClO}_{4}\right)_{2}$, 用 $1 \mathrm{~mL}$ 甲醇溶解, 然后将三肽溶液 $(1 \mathrm{mg} / \mathrm{mL})$ 和 $\mathrm{Cu}(4 \mathrm{Cl}$-tpy $)\left(\mathrm{ClO}_{4}\right)_{2}$ 溶液 $(1 \mathrm{mg} / \mathrm{mL})$ 按摩尔 比 5:1混合后, 用 $\mathrm{CH}_{3} \mathrm{OH}: \mathrm{H}_{2} \mathrm{O}=1: 1$ 稀释 20 倍, 然后用注 射泵将此混合溶液注入到ESI离子源中.

\subsection{4 质谱条件}

电喷雾离子源; 正离子模式; 雾化气压力7.3 psi; 毛细管电压 $4500 \mathrm{~V}$; End Plate Offset $500 \mathrm{~V}$; 流速为 $150 \mu \mathrm{L} / \mathrm{h}$; 干燥气: $\mathrm{N}_{2}$; 干燥气温度: $100{ }^{\circ} \mathrm{C}$; 干燥气流 速: $4 \mathrm{~L} / \mathrm{min}$; 隔离宽度: $1 \mathrm{~m} / \mathrm{z}$; Max Accu Time: $10 \mathrm{~ms}$; 碰撞气: $\mathrm{He}$; 激发电压: $0.25-0.43 \mathrm{~V}$; 扫描范围: $50-3000 \mathrm{~m} / \mathrm{z}$.

\subsection{5 计算条件}

本文中的所有计算是应用Gaussian 09程序, 采用 密度泛函理论(DFT) 方法 ${ }^{[36,37]}$, 使用6-31+g(d, p) 基组进 行结构优化. 所有结构都进行了频率校正, 所有过渡态 都采用内部反映坐标(the intrinsic reaction coordinate, IRC)的方法 ${ }^{[38]}$ 进行确认.

\section{3 结果与讨论}

\section{1 产生AYG自由基离子的前驱体研究}

我们通过 $[\mathrm{Cu} \text { (4Cl-tpy)Peptide }]^{\circ+}$ 的CID反应, 成功 制备了 $\mathrm{AYG}$ 的两种自由基离子 $[\mathrm{AYG}]^{\circ+}$ (由 $[\mathrm{Cu}(4 \mathrm{Cl}-$ tpy)(AYG) $]^{2+}$ 产生)(图S2)和 $\left[\mathrm{AYG}^{\bullet}\right]^{+}$(由[AYM $]^{\bullet+}$ 产生) (图 3(a)), 并探索 $\left[\mathrm{AYG}^{\circ}\right]^{+}$的两种可能前驱体 $-[\mathrm{AYM}]^{\bullet+}$ 和 $[\mathrm{AYW}]^{\bullet+}$ 的气相碎裂机理(图4), 其中, $[\mathrm{AYM}]^{\bullet+}$ 和 $[\mathrm{AYW}]^{\bullet+}$ 分别由 $[\mathrm{Cu}(4 \mathrm{Cl}-\mathrm{tpy})(\mathrm{AYM})]^{2+}$ 和 $\left[\mathrm{Cu}(4 \mathrm{Cl} \text {-tpy)(AYW) }]^{2+}\right.$ 产生. 图3(a) 是 $[\mathrm{AYM}]^{++}$的CID谱 图. [AYM] ${ }^{\bullet+}\left(m / z\right.$ 383.05) 的主要解离产物是 $\left[\mathrm{x}_{2}+\mathrm{H}\right]^{\bullet+}(\mathrm{m} / \mathrm{z}$ $339.99)$ 和 $\left[\mathrm{AYG}^{\circ}\right]^{+}\left(\mathrm{m} / z\right.$ 309.01). 此外, 还有少量的 $\left[\mathrm{b}_{2}\right.$ $-\mathrm{H}]^{\circ+}(m / z \quad 233.98) 、\left[\mathrm{y}_{1}+2 \mathrm{H}\right]^{+}(m / z \quad 150.00) 、[\mathrm{AYM}$ $\left.-\mathrm{H}_{2} \mathrm{O}\right]^{-+}\left(m / z\right.$ 365.00)、 $\left[\mathrm{x}_{2}+\mathrm{H}-\mathrm{H}_{2} \mathrm{O}\right]^{-+}\left(m / z\right.$ 322.02)、 $\left[\mathrm{z}_{2}\right.$ $-\mathrm{H}]^{\bullet+}(m / z \quad 294.93)$ 及其碎片离子 $\left[\mathrm{z}_{2}-\mathrm{H}-\mathrm{CO}_{2}\right]^{\bullet+}(\mathrm{m} / \mathrm{z}$ 250.92). 图3(b) 是 $[\mathrm{AYW}]^{\bullet+}$ 的CID谱图. [AYW] ${ }^{\circ+}(\mathrm{m} / \mathrm{z}$ $438.11)$ 的主要解离路径是丢失一分子 $\mathrm{CO}_{2}$ 产生 $[\mathrm{AYW}$ $\left.-\mathrm{CO}_{2}\right]^{0+}\left(\mathrm{m} / \mathrm{z}\right.$ 394.11). 此外, 还有 $\left[\mathrm{AYW}-\mathrm{CO}_{2}\right]^{\bullet+}$ 进一步 丢失一分子中性自由基(116 Da)产生的 $\left[\mathrm{AYW}-\mathrm{CO}_{2}\right.$ $-116]^{\bullet+}(m / z \quad 278.02)$ 以及 $\beta$ 自由基诱导产生的 $\left[\mathrm{c}_{2}\right.$ $+2 \mathrm{H}]^{+}(\mathrm{m} / \mathrm{z} 252.00)$ 碎片离子. 

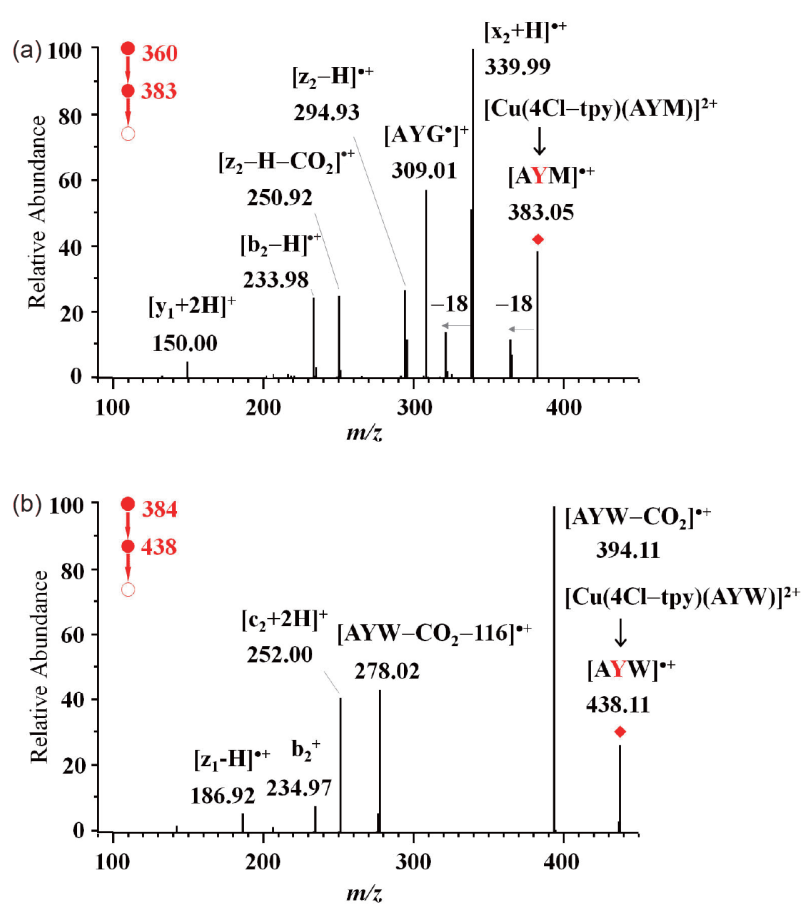

图 3 (由 $[\mathrm{Cu}(4 \mathrm{Cl}-\mathrm{tpy})(\mathrm{AYM})]^{2+}$ 产生) $[\mathrm{AYM}]^{*+}$ (a)和(由 $[\mathrm{Cu}$ (4Cl-tpy)(AYW) $]^{2+}$ 产生) $[\mathrm{AYW}]^{*+}$ (b)的CID谱图(网络版彩图) Figure $3 \mathrm{CID}$ spectra of $[\mathrm{AYM}]^{++}$(a) and $[\mathrm{AYW}]^{++}$(b) generated from $\left[\mathrm{Cu}(4 \mathrm{Cl} \text {-tpy) }(\mathrm{AYM})]^{2+}\right.$ and $\left[\mathrm{Cu}(4 \mathrm{Cl} \text {-tpy)(AYW) }]^{2+}\right.$, respectively (color online).
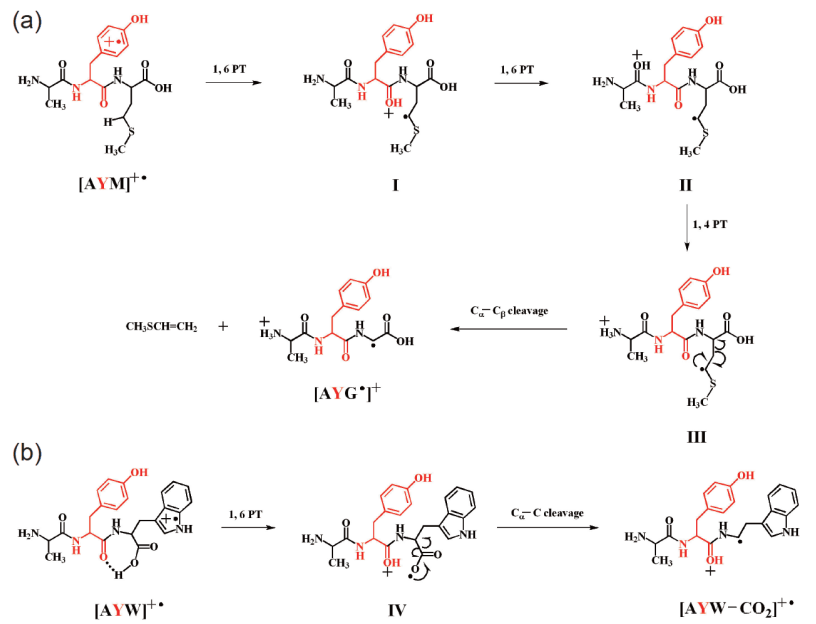

图 $4\left[[\mathrm{AYM}]^{++}\right.$(a) 和 $[\mathrm{AYW}]^{++}$(b)的气相裂解机理(网络版彩 图)

Figure 4 Gas-phase fragmentation mechanisms of $[\mathrm{AYM}]^{\bullet+}$ (a) and $[\mathrm{AYW}]^{++}$(b) (color online).

图4分别给出了 $[\mathrm{AYM}]^{\bullet+}$ 和 $[\mathrm{AYW}]^{\bullet+}$ 的气相裂解机 理. Hopkinson等 ${ }^{[30]}$ 曾探讨过 $[\mathrm{MG}]^{\bullet+}$ 和 $[\mathrm{GM}]^{\bullet+}$ 的裂解机 理, $[\mathrm{GM}]^{\bullet+}$ 中甲硫氨酸残基(M)的 $\gamma-\mathrm{H}$ 可以迁移到氨基
$\mathrm{N}$ 原子上，然后通过 $\gamma$ 自由基诱导的 $\mathrm{C}_{\alpha}-\mathrm{C}_{\beta}$ 键断裂产生 $\left[\mathrm{GG}^{\bullet}\right]^{+}$, 而 $[\mathrm{MG}]^{\bullet+}$ 中甲硫氨酸残基 $(\mathrm{M})$ 的 $\gamma-\mathrm{H}$ 在氨基酸 内的迁移受到阻碍，因此， $[M G]^{\bullet+}$ 没有产生 $\left[\mathrm{G}^{\circ} \mathrm{G}\right]^{+}$. 根 据 $[\mathrm{GM}]^{\circ+}$ 产生 $\left[\mathrm{GG}^{\circ}\right]^{+}$的机理, 我们推测了 $[\mathrm{AYM}]^{\circ+}$ 产生 $\left[\mathrm{AYG}^{\circ}\right]^{+}$的机理. 与 $[\mathrm{GM}]^{\circ+}$ 不同的是, $[\mathrm{AYM}]^{\circ+}$ 是 $\pi$ 自由 基离子(即自由基和电荷都在酪氨酸( $\mathrm{Y}$ )的苯环上)，而 $[\mathrm{GM}]^{\bullet+}$ 的自由基和电荷都在甲硫氨酸残基 $(\mathrm{M})$ 的 $\mathrm{S}$ 原 子上. 图4(a)给出了 $[A Y M]^{\circ+}$ 中甲硫氨酸残基 $(\mathrm{M})$ 的 $\mathrm{C}_{\alpha}-\mathrm{C}_{\beta}$ 键断裂产生 $\left[\mathrm{AYG}^{\circ}\right]^{+}$的机理，质子从甲硫氨酸残 基( $\mathrm{M})$ 的 $\mathrm{C}_{\gamma}$ 上迁移到第二个羰基(即酪氨酸残基的羰 基)O原子上，然后从第二个羰基(即酪氨酸残基的羰 基) $\mathrm{O}$ 原子上迁移到第一个羰基(即丙氨酸残基的羰基) $\mathrm{O}$ 原子上, 最后迁移到氨基 $\mathrm{N}$ 原子上, $\gamma$ 自由基诱导甲硫 氨酸残基 $(\mathrm{M})$ 的 $\mathrm{C}_{\alpha}-\mathrm{C}_{\beta}$ 键断裂丢失 $\mathrm{CH}_{3} \mathrm{SCH}=\mathrm{CH}_{2} \quad$ (74 $\mathrm{Da})$ 产生 $\left[\mathrm{AYG}^{\circ}\right]^{+}$产物离子.

与 $[\mathrm{AYM}]^{\bullet+}$ 裂解途径不同的是, $[\mathrm{AYW}]^{\bullet+}$ 没有通过 色氨酸残基 $(\mathrm{W})$ 的 $\mathrm{C}_{\alpha}-\mathrm{C}_{\beta}$ 键断裂产生 $\left[\mathrm{AYG}^{\circ}\right]^{+}(\mathrm{m} / \mathrm{z}$ $309.01)$, 而是通过羧基 $(-\mathrm{COOH})$ 上的质子迁移到第二 个羰基(即酪氨酸残基的羰基) $\mathrm{O}$ 原子上产生羧基氧自 由基离子, 此自由基离子诱导色氨酸残基 $(\mathrm{W})$ 的 $\mathrm{C}_{\alpha}-\mathrm{C}$ 键断裂产生 $\left[\mathrm{AYW}-\mathrm{CO}_{2}\right]^{\bullet+}(\mathrm{m} / \mathrm{z}$ 394.11)(图4(b)), 此机 理与 $\mathrm{Chu}$ 等 ${ }^{[10]}$ 研究的 $[\mathrm{GGW}]^{\bullet+}$ 失去一分子 $\mathrm{CO}_{2}$ 的机理 类似. 与甲硫氨酸 $(M)$ 不同的是, 当色氨酸残基 $(W)$ 在 $N$ 端时, $\mathrm{W}$ 可以先发生 1,4 质子迁移再通过 $\mathrm{C}_{\alpha}-\mathrm{C}_{\beta}$ 键断裂 产生 $\alpha$ 自由基离子 ${ }^{[29]}$. Siu等 ${ }^{[29]}$ 研究的 $[\mathrm{WGG}]^{\circ+}$ 通过色 氨酸残基 $(\mathrm{W})$ 的侧链丢失产生了 $\left[\mathrm{G}^{\circ} \mathrm{GG}\right]^{+}$, 以及我们由 $[\mathrm{WYA}]^{\bullet+}$ 的CID反应成功制备 $\left[\mathrm{G}^{\circ} \mathrm{YA}\right]^{+}$离子都证实了这 一点(图S3(a)). 需要说明的是, [WYA $]^{\circ+} 、[\mathrm{AYM}]^{\circ+}$ 和 $[\mathrm{AYW}]^{\circ+}$ 的主要碎片离子可通过将上述三肽中的丙氨 酸 $(A)$ 置换成甘氨酸 $(G)$ 进行验证, 相应置换产物 $\left([\mathrm{WYG}]^{\circ+} 、[\mathrm{GYM}]^{\circ+}\right.$ 和 $[\mathrm{GYW}]^{\circ+}$ )的验证谱图参见图 $\mathrm{S} 3$ (b)和图 $S 4(a, b)$.

\subsection{AYG自由基离子的气相稳定结构}

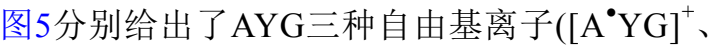
$\left[\mathrm{AYG}^{\bullet}\right]^{+}$和 $[\mathrm{AYG}]^{\bullet+}$ ) 的气相最稳定结构 (上边数字代表 $0 \mathrm{~K}$ 时的焓变, 下边斜体数字代表 $298 \mathrm{~K}$ 时的自由能变). 与 $\mathrm{GGG}^{[31]}$ 和 $\mathrm{GGW}^{[10]}$ 系列相同的是, $\mathrm{AYG}$ 最稳定的自 由基离子是 $\left[\mathrm{A}^{*} \mathrm{YG}\right]^{+}$, 第一个羰基(即丙氨酸残基的羰 基) $\mathrm{O}$ 上的质子与第二个羰基(即酪氨酸残基的羰基) $\mathrm{O}$ 形成较强的氢键 $\left(\left[\mathrm{CO}_{1}-\mathrm{H}^{+} \cdots \mathrm{O}_{2} \mathrm{C}\right]\right.$, 氢键键长 $\left.1.459 \AA\right)$. 

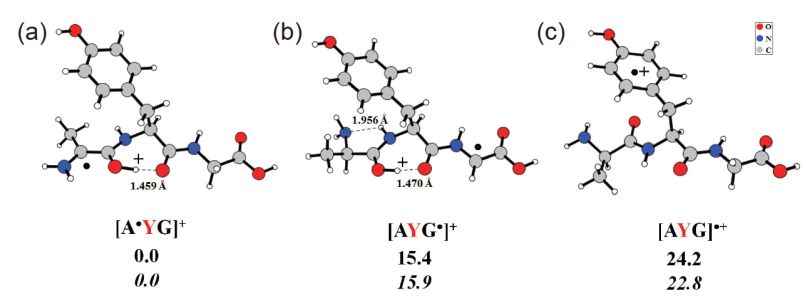

图 5 (a) $\left[\mathrm{A}^{*} \mathrm{YG}\right]^{+}$, (b) $\left[\mathrm{AYG}^{\bullet}\right]^{+}$和(c) $[\mathrm{AYG}]^{\bullet+}$ 的气相稳定结 构 (color scheme: $\mathrm{C}=$ 灰色; $\mathrm{O}=$ 红色; $\mathrm{N}=$ 蓝色; $\mathrm{H}=$ 白色; 上边数 字: $0 \mathrm{~K}$ 时的焓变, 斜体数字: $298 \mathrm{~K}$ 时的自由能). 所有能量 $(\mathrm{kcal} / \mathrm{mol})$ 是相对于 $\left[\mathrm{A}^{*} \mathrm{YG}\right]^{+}$的相对能量, 是由B3LYP/6-31+ $+\mathrm{G}(\mathrm{d}, \mathrm{p})$ 计算得到(网络版彩图)

Figure 5 Optimized geometries of the lowest-energy structures of (a) $\left[\mathrm{A}^{\circ} \mathrm{YG}^{+}\right]^{+}$, (b) $\left[\mathrm{AYG}^{*}\right]^{+}$and (c) $[\mathrm{AYG}]^{\circ+}$ (color scheme: $\mathrm{C}=$ grey; $\mathrm{O}=$ red; $\mathrm{N}=$ blue; $\mathrm{H}=$ white; the upper numbers: enthalpies at $0 \mathrm{~K}$, the lower italicized numbers: free energies at $298 \mathrm{~K}$ ). All energies (in kcal $/ \mathrm{mol}$ ) are relative energy to $\left[\mathrm{A}^{\circ} \mathrm{YG}\right]^{+}$and are calculated at the $\mathrm{B} 3 \mathrm{LYP} / 6-31+$ $+\mathrm{G}(\mathrm{d}, \mathrm{p})$ levels (color online).

因为 $\left[\mathrm{A}^{\bullet} \mathrm{YG}\right]^{+}$的自由基左右分别是强的给电子基团 $\left(-\mathrm{NH}_{2}\right)$ 和强的吸电子基团 $\left([-\mathrm{C}(\mathrm{OH}) \mathrm{NH}]^{+}\right)$, 强的“推拉 效应, ${ }^{[31]}$ 使得 $\left[\mathrm{A}^{\bullet} \mathrm{YG}\right]^{+}$比另外两种自由基离子 $\left(\left[\mathrm{AYG}^{\bullet}\right]^{+}\right.$ 和 $[\mathrm{AYG}]^{\bullet+}$ )更稳定.

$\left[\mathrm{AYG}^{*}\right]^{+}$的电荷和自由基分别在第一个羰基(即丙 氨酸残基的羰基) $\mathrm{O}$ 上和甘氨酸的 $\mathrm{C}_{\alpha}$ 上, 第一个羰基(即 丙氨酸残基的羰基) $\mathrm{O}$ 上的质子与第二个羰基(即酪氨 酸残基的羰基) $\mathrm{O}$ 形成一个强的氢键 $\left(\left[\mathrm{CO}_{1}-\mathrm{H}^{+} \cdots \mathrm{O}_{2} \mathrm{C}\right]\right.$, 氢键键长 $1.470 \AA$ ), 第一个氨基(即丙氨酸残基氨基) $\mathrm{N}$ 与酪氨酸残基 $\mathrm{N}$ 上的 $\mathrm{H}$ 形成一个较弱的氢键 $\left(\left[\mathrm{N}_{1} \cdots \mathrm{H}^{+}\right.\right.$ $\left.-\mathrm{N}_{2} \mathrm{C}\right]$, 氢键键长 $\left.\sim 1.956 \AA\right)$, 因为 $\left[\mathrm{AYG}^{\circ}\right]^{+}$的 $C$ 端酰胺键 $(1.356 \AA)$ 长于 $\left[\mathrm{A}^{\bullet} \mathrm{YG}\right]^{+}$的 $\mathrm{C}$ 端酰胺键键长 $(1.332 \AA)$, $\left[\mathrm{AYG}^{\circ}\right]^{+}$的电荷很难离域到 $\mathrm{C}$ 端氨基酸残基上, 电荷与 自由基处于分离的状态，而且没有“推拉效应”，所以 其能量比 $\left[\mathrm{A}^{\bullet} \mathrm{YG}\right]^{+}$高 $15.4 \mathrm{kcal} / \mathrm{mol}$. $\left[\mathrm{GGG}^{\circ}\right]^{+}$与 $\left[\mathrm{AYG}^{\circ}\right]^{+}$ 类似，电荷和自由基也分别在第一个羰基(即甘氨酸残 基的羰基 $) \mathrm{O}$ 上和甘氨酸的 $\mathrm{C}_{\alpha}$ 上，而 $\left[\mathrm{GGW}^{\circ}\right]^{+}$电荷和自 由基分别在色氨酸的羧基 $\mathrm{O}$ 上和色氨酸的 $\mathrm{C}_{\alpha}$ 上, 这是 因为色氨酸的质子亲和势 $(\mathrm{PA}, 223.9 \mathrm{kcal} / \mathrm{mol})^{[39]}$ 高于 甘氨酸和丙氨酸 $($ 甘氨酸和丙氨酸的PA值分别是 210.5 和 $214.2 \mathrm{kcal} / \mathrm{mol})^{[39]}$.

酪氨酸 $(Y)$ 的存在对 $\left[A^{\bullet} Y G\right]^{+}$和 $\left[A Y G^{\bullet}\right]^{+}$两种 $\alpha$ 自由 基离子的结构和稳定性没有太大影响，但是当电荷和 自由基都位于酪氨酸残基 $(\mathrm{Y})$ 的苯环上时, $[\mathrm{AYG}]^{\circ+}$ 的 能量比最稳定的自由基离子 $\left[\mathrm{A}^{\circ} \mathrm{YG}\right]^{+}$高 $24.2 \mathrm{kcal} / \mathrm{mol}$. 与 $[\mathrm{GGW}]^{\circ+}$ (电荷和自由基都位于色氨酸残基 $(W)$ 的吲
哚环上)相比, [GGW $]^{-+}$的能量比 $\left[\mathrm{G}^{\circ} \mathrm{GW}\right]^{+}$仅高 $1.5 \mathrm{kcal} /$ $\mathrm{mol}^{[10]}$, 这是因为色氨酸具有的大的共轭体系-吲哚环, 其离域能力比酪氨酸的芳香环强, 所以 $[\mathrm{GGW}]^{\bullet+}$ 比 $[\mathrm{AYG}]^{\bullet+}$ 要稳定得多.

\subsection{AYG和GYG自由基离子气相裂解行为比较}

图6是 $[\mathrm{AYG}]^{\bullet+}$ 和 $\left[\mathrm{AYG}^{\bullet}\right]^{+},\left[\mathrm{G}^{\bullet} \mathrm{YG}\right]^{+} 、[\mathrm{GYG}]^{\bullet+}$ 和 $\left[\mathrm{GYG}^{\bullet}\right]^{+}$(分别由 $\left[\mathrm{Cu}(4 \mathrm{Cl} \text {-tpy) }(\mathrm{AYG})]^{2+}\right.$ 和 $[\mathrm{AYM}]^{\bullet+}$, $[\mathrm{WYG}]^{\circ+} 、[\mathrm{Cu}(4 \mathrm{Cl}-\mathrm{tpy})(\mathrm{GYG})]^{2+}$ 和 $[\mathrm{GYM}]^{\circ+}$ 产生)的 CID谱图. $\left.{ }^{2} \mathrm{AYG}\right]^{\bullet+}$ 的主要解离产物是 $\left[\mathrm{x}_{2}+\mathrm{H}\right]^{\bullet+}(\mathrm{m} / \mathrm{z}$ 265.93), 此外, 还有少量的 $\left[\mathrm{c}_{2}+2 \mathrm{H}\right]^{+}(m / z$ 251.84), 它们 都是自由基诱导的裂解反应产物. 其中, $\left[\mathrm{x}_{2}+\mathrm{H}\right]^{\bullet+}$ 是 $[\mathrm{AYG}]^{\bullet+}$ 的 $\mathrm{N}$ 端 $\mathrm{C}_{\alpha}-\mathrm{C}$ 键直接断裂产生的碎片离子, $\left[\mathrm{c}_{2}\right.$ $+2 \mathrm{H}]^{+}$是 $\beta$ 自由基诱导 $\mathrm{N}-\mathrm{C}_{\alpha}$ 键断裂产生的碎片离子, 此 结果和 $\mathrm{Chu}$ 等 ${ }^{[33]}$ 的结果相同. 有趣的是, 我们通过 $[\mathrm{AYM}]^{\bullet+}$ 的 $\mathrm{CID}$ 反应得到了 $\left[\mathrm{AYG}^{\bullet}\right]^{+}$离子, $\left[\mathrm{AYG}^{\bullet}\right]^{+}$和 $[\mathrm{AYG}]^{-+}$的CID谱图基本一样(图6(a,b)), 其主要解离 产物都是 $\left[\mathrm{x}_{2}+\mathrm{H}\right]^{\bullet+}(\mathrm{m} / \mathrm{z} 265.93)$, 说明 $\left[\mathrm{AYG}^{\circ}\right]^{+}$和 $\left[\mathrm{AYG}^{\circ}\right]^{+}$ 在解离之前已发生了异构反应. 而 $\left[\mathrm{A}^{\circ} \mathrm{YG}\right]^{+}$的主要解离 路径是电荷诱导的第二个酰胺键的断裂, 相应的产物 离子是 $\left[b_{2}-H\right]^{\bullet+[33]}$, 说明 $\left[\mathrm{A}^{\bullet} \mathrm{YG}\right]^{+}$与另外两种离子是不 可能发生异构的.

$\left[\mathrm{G}^{\circ} \mathrm{YG}\right]^{+}$的解离路径与 $\left[\mathrm{A}^{\bullet} \mathrm{YG}\right]^{+}$相同 ${ }^{[33]}$, 都是通过 电荷诱导酰胺键的断裂产生 $\left[\mathrm{b}_{2}-\mathrm{H}\right]^{\bullet+}$ 离子 $(m / z$ 219.92) (图6(c)). b/y离子的形成是一个竞争过程, 自由基离子 的 $\mathrm{N}$ 端碎片和 $\mathrm{C}$ 端碎片 $\mathrm{PA}$ 值的相对大小决定最终产 物 ${ }^{[10]}$. $\left[\mathrm{A}^{\bullet} \mathrm{YG}\right]^{+}$和 $\left[\mathrm{G}^{\circ} \mathrm{YG}\right]^{+}$的产物离子只有 $\left[\mathrm{b}_{2}-\mathrm{H}\right]^{\bullet+}$ 却 没有 $\mathrm{y}_{1}$ 离子, 其原因是 $\left[A^{\bullet} Y G\right]^{+}$和 $\left[G^{\bullet} Y G\right]^{+}$的 $N$ 端碎片 的PA值分别是 227.4 和 $225.2 \mathrm{kcal} / \mathrm{mol}, \mathrm{C}$ 端碎片的PA值 都是 $197.5 \mathrm{kcal} / \mathrm{mol}$ (表1), 即 $\mathrm{N}$ 端碎片的PA值明显大于 $\mathrm{C}$ 端碎片. $\left[\mathrm{G}^{\bullet} \mathrm{YG}\right]^{+}$与 $[\mathrm{GYG}]^{\bullet+}$ 和 $\left[\mathrm{GYG}^{\bullet}\right]^{+}$相比, 解离产 物明显不同, 说明 $\left[\mathrm{G}^{\circ} \mathrm{YG}\right]^{+}$与它们不能异构.

与 $[\mathrm{AYG}]^{\bullet+}$ 和 $\left[\mathrm{AYG}^{\bullet}\right]^{+}$的裂解行为不同的是, $[\mathrm{GYG}]^{\bullet+}$ 主要通过 $\mathrm{N}-\mathrm{C}_{\alpha}$ 键断裂和 $\mathrm{CO}_{2}$ 的进一步丢失分 别产生 $\left[\mathrm{z}_{2}-\mathrm{H}\right]^{\bullet+}(\mathrm{m} / \mathrm{z} \quad 220.90)$ 和 $\left[\mathrm{z}_{2}-\mathrm{H}-\mathrm{CO}_{2}\right]^{\bullet+}(\mathrm{m} / \mathrm{z}$ $176.94)$ 碎片离子. 此外, 还产生少量 $\left[\mathrm{b}_{2}-\mathrm{H}\right]^{\bullet+}(\mathrm{m} / \mathrm{z}$ $220.01),\left[\mathrm{GG}^{\bullet} \mathrm{G}\right]^{+}(\mathrm{m} / \mathrm{z} \quad 188.76)$ 和 $\left[\mathrm{GYG}-\mathrm{H}_{2} \mathrm{O}\right]^{\bullet+}(\mathrm{m} / \mathrm{z}$ 277.11)碎片离子(图6(d)). $\left[\mathrm{GYG}^{\circ}\right]^{+}$的主要产物离子是 $\mathrm{b}_{2}{ }^{+}(m / z \quad 220.89) 、\left[\mathrm{z}_{2}-\mathrm{H}\right]^{\bullet+}\left(\begin{array}{ll}m / z & 220.89)\end{array}\right.$ (即在 $m / z$ 220.89 处的离子是 $\mathrm{b}_{2}{ }^{+}$和 $\left[\mathrm{z}_{2}-\mathrm{H}\right]^{\circ+}$ 的混合物 $)$ 和 $\left[\mathrm{GYG}^{\circ}-\right.$ $\left.\mathrm{H}_{2} \mathrm{O}-\mathrm{NH}=\mathrm{CH}_{2}\right]^{+}\left(m / z \text { 247.93) 碎片离子. 此外, [GYG }{ }^{\circ}\right]^{+}$ 


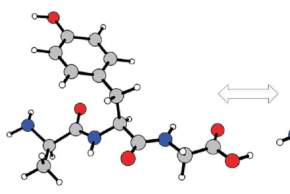

AYG

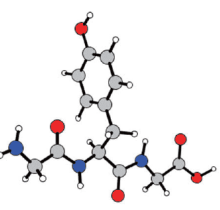

GYG (a)

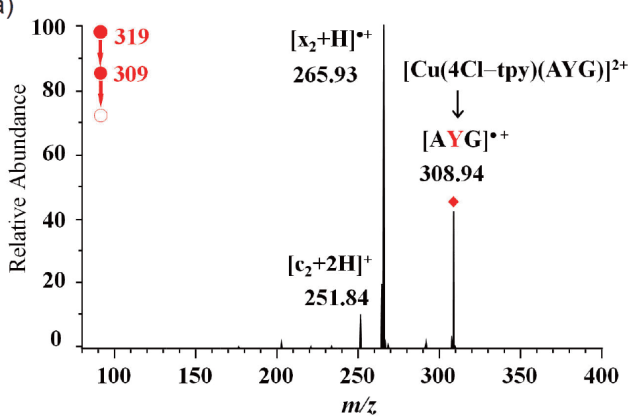

(b)

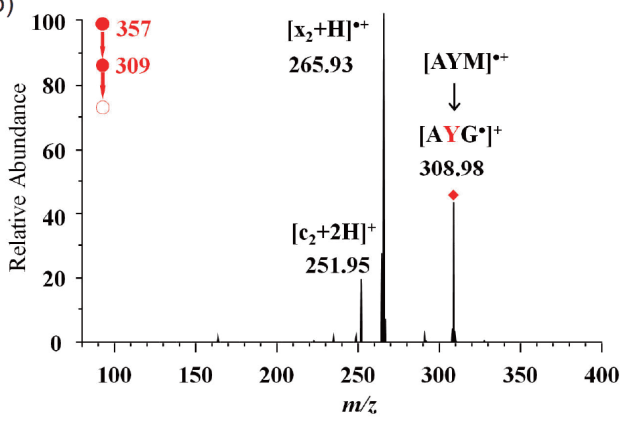

(c)

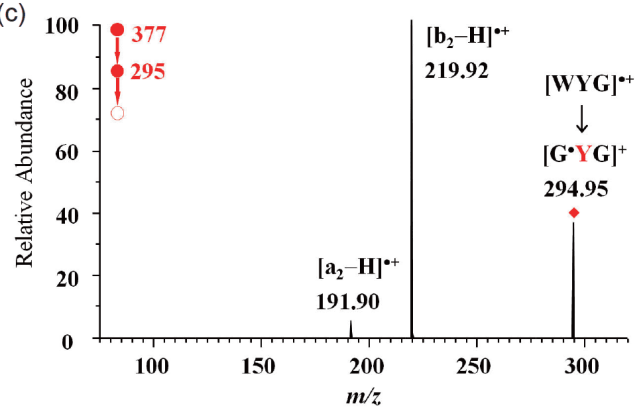

(d)

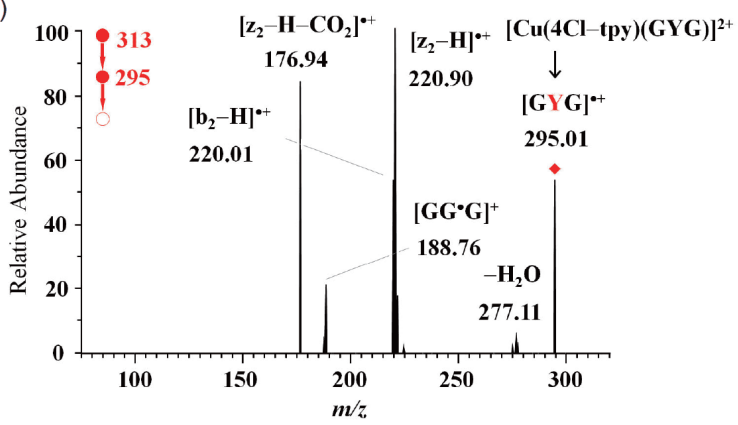

(e)

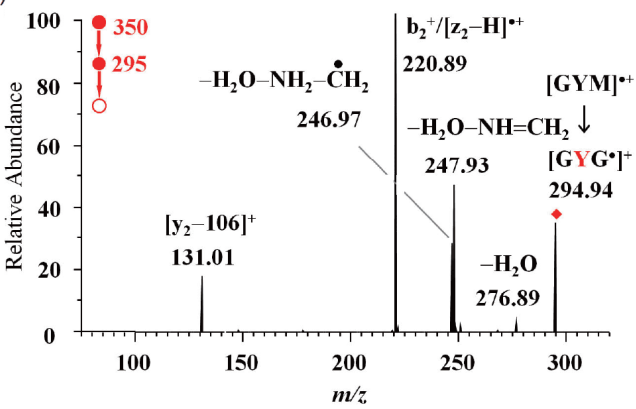

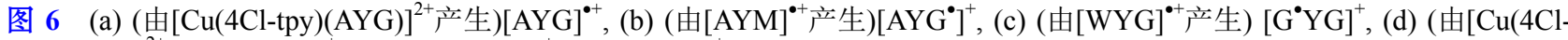
tpy)(GYG) $]^{2+}$ 产生) $[\mathrm{GYG}]^{++}$和(e) (由[GYM $]^{++}$产生) $\left[\mathrm{GYG}^{\circ}\right]^{+}$的CID谱图(网络版彩图)

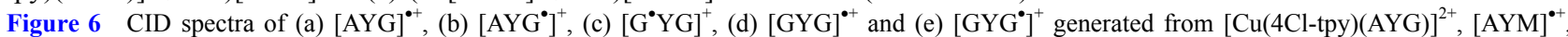
$[\mathrm{WYG}]^{*+},[\mathrm{Cu}(4 \mathrm{Cl}-\mathrm{tpy})(\mathrm{GYG})]^{2+}$ and $[\mathrm{GYM}]^{*+}$, respectively (color online).

表 $1\left[\mathrm{~A}^{*} \mathrm{YG}\right]^{+}$和 $\left[\mathrm{G}^{*} \mathrm{YG}\right]^{+}$的 $\mathrm{N}$ 端和 $\mathrm{C}$ 端碎片的PA值比较(所 有的PAs是由B3LYP/6-31++G(d,p)计算得到)

Table 1 Proton affinities of N-terminal and C-terminal fragments from $\left[\mathrm{A}^{*} \mathrm{YG}\right]^{+}$and $\left[\mathrm{G}^{*} \mathrm{YG}\right]^{+}$(all PAs are calculated at the B3LYP/6-31+ $+\mathrm{G}(\mathrm{d}, \mathrm{p})$ level)

\begin{tabular}{|c|c|c|c|}
\hline \multirow{2}{*}{ 中间体 } & \multicolumn{2}{|c|}{ 碎片 } & \multirow{2}{*}{$\mathrm{PA}(\mathrm{kcal} / \mathrm{mol})$} \\
\hline & 不带电(M) & {$[\mathrm{M}+\mathrm{H}]^{+}$} & \\
\hline & N端 & & \\
\hline & & {$\left[\mathrm{b}_{2}-\mathrm{H}\right]^{++}$} & $\begin{array}{l}225.2(\mathrm{R}=\mathrm{H}) \\
227.4\left(\mathrm{R}=\mathrm{CH}_{3}\right)\end{array}$ \\
\hline & & {$\left[\mathrm{y}_{1}+2 \mathrm{H}\right]^{+}$} & 197.5 \\
\hline
\end{tabular}

还产生了少量 $\left[\mathrm{GYG}^{\bullet}-\mathrm{H}_{2} \mathrm{O}\right]^{+}\left(\mathrm{m} / z\right.$ 276.89), $\left[\mathrm{GYG}^{\bullet}-\mathrm{H}_{2} \mathrm{O}\right.$ $\left.-\mathrm{NH}-\mathrm{C}^{\bullet} \mathrm{H}_{2}\right]^{+}(m / z \quad 246.97)$ 和 $\left[\mathrm{y}_{2}-106\right]^{+}(m / z \quad 131.01)$. $[\mathrm{GYG}]^{\bullet+}$ 和 $\left[\mathrm{GYG}^{\bullet}\right]^{+}$的解离产物不完全相同, 说明 $\left[\mathrm{GYG}^{\bullet}\right]^{+}$和 $[\mathrm{GYG}]^{\bullet+}$ 可能在解离之前发生了部分异构. 因为 GYG的结构对称，其骨架裂解的产物离子可能具 有相同的质荷比(如 $\left[\mathrm{z}_{2}-\mathrm{H}\right]^{+{ }^{*}}$ 和 $\mathrm{b}_{2}{ }^{+}$的 $m / z$ 都是 221 ), 所以 $\left.\left[\mathrm{GYG}^{\circ}\right]^{+} 、 \mathrm{G}^{*} \mathrm{YG}\right]^{+}$和 $\left[\mathrm{GYG}^{*}\right]^{+}$的主要碎片离子可分别 通过 $[\mathrm{GYA}]^{\circ+} 、\left[\mathrm{G}^{\circ} \mathrm{YA}\right]^{+}$和 $m / z$ 220.89处离子的四级串 联质谱图证明(图S5(a c )). 进一步观察 $m / z$ 220.89离子 的 CID 反应可以看到分别失去一分子 $\mathrm{NH}_{3}$ 和一分子 $\mathrm{CO}_{2}$ 的反应(图 $\mathrm{S} 5(\mathrm{c})$ ). 丢失 $\mathrm{NH}_{3}$ 的反应说明该离子是 $\mathrm{N}$ 端碎片离子 $\mathrm{b}_{2}^{+}$, 丢失 $\mathrm{CO}_{2}$ 则说明该离子是 $\mathrm{C}$ 端碎片离 
子 $\left[\mathrm{z}_{2}-\mathrm{H}\right]^{*+}$. 所以, $\left[\mathrm{GYG}^{\circ}\right]^{+}$位于 $m / z 220.89$ 处的离子是 $\mathrm{b}_{2}{ }^{+}$和 $\left[\mathrm{z}_{2}-\mathrm{H}\right]^{\circ+}$ 的混合峰. 具有不同自由基位点 $A Y G$ 和 GYG自由基离子的主要碎片离子已在表S1(网络版补 充材料)中总结.

我们通过DFT计算得到了AYG自由基离子的气相 异构/解离能垒以及 $[\mathrm{GYG}]^{\circ+} \mathrm{N}$ 端 $\mathrm{C}_{\alpha}-\mathrm{C}$ 的解离能垒, 并 以此为依据来解释 $[\mathrm{AYG}]^{\bullet+}$ 和 $[\mathrm{GYG}]^{\bullet+}$ 的不同气相裂解 行为.

\subsection{AYG和GYG自由基离子的理论计算}

\subsubsection{AYG自由基离子气相解离/异构反应机理的 理论研究}

图7(a)是 $A Y G$ 自由基离子的异构/解离反应势能 图. $\left[\mathrm{A}^{\bullet} \mathrm{YG}\right]^{+}$到 $[\mathrm{AYG}]^{\bullet+}$ 的异构需要 $\left[\mathrm{A}^{\bullet} \mathrm{YG}\right]^{+}$的第一个羰 基(即丙氨酸残基的羰基) $\mathrm{O}$ 上的 $\mathrm{H}$ 迁移到丙氨酸残基 的 $\mathrm{C}_{\alpha}$ 上, 这个过程所需的能量为 $55.0 \mathrm{kcal} / \mathrm{mol},\left[\mathrm{A}^{\circ} \mathrm{YG}\right]^{+}$ 到 $\left[\mathrm{AYG}^{\circ}\right]^{+}$的异构需要甘氨酸残基的 $\mathrm{C}_{\alpha}$ 上的 $\mathrm{H}$ 迁移到 丙氨酸残基的 $\mathrm{C}_{\alpha}$ 上，这个过程所需的能量为 $60.2 \mathrm{kcal} /$ $\mathrm{mol}$, 而 $\left[\mathrm{AYG}^{\bullet}\right]^{+}$到 $[\mathrm{AYG}]^{\bullet+}$ 的异构需要 $\left[\mathrm{AYG}^{\bullet}\right]^{+}$的第一 个羰基(即丙氨酸残基的羰基) $\mathrm{O}$ 上的 $\mathrm{H}$ 迁移到甘氨酸 残基的 $\mathrm{C}_{\alpha}$ 上, 这个过程所需的能量为 $47.4 \mathrm{kcal} / \mathrm{mol}$. 通 过比较这三个异构反应的活化能, 我们可以得出结论: $\left[\mathrm{A}^{\bullet} \mathrm{YG}\right]^{+}$不能与另外两种自由基离子异构. 此结论与我 们的实验结果相符.

为了深入探讨 $\left.\mathrm{AYG}^{\bullet}\right]^{+}$和 $[\mathrm{AYG}]^{++} \mathrm{CID}$ 谱图相同的 原因, 我们又计算了 $\left[\mathrm{AYG}^{\bullet}\right]^{+}$和 $[\mathrm{AYG}]^{\bullet+}$ 的解离能垒. $[\mathrm{AYG}]^{-+}$产生 $\left[\mathrm{x}_{2}+\mathrm{H}\right]^{\bullet+}$ 产物离子涉及两个过程(图7(b)): 丙氨酸残基的 $\mathrm{C}_{\alpha}-\mathrm{C}$ 键断裂经过过渡态(TS6)产生分子 离子复合物(COM 1), COM 1的自由基和电荷分别位 于第一个羰基(即丙氨酸残基的羰基) $\mathrm{C}$ 上和亚胺的 $\mathrm{N}$ 上，亚胺 $\mathrm{N}$ 上的 $\mathrm{H}$ 与第一个羰基(即丙氨酸残基的羰基) $\mathrm{O}$ 形成一个较强的氢键 $\left(\left[\mathrm{N}_{1}-\mathrm{H}^{+} \cdots \mathrm{O}_{1} \mathrm{C}\right]\right.$, 氢键键长 $\sim 1.716 \AA$ ), 此过程的能垒是 $34.7 \mathrm{kcal} / \mathrm{mol}$; 然后, 苯环 上的电子转移到第一个羰基(即丙氨酸残基的羰基) $\mathrm{C}$ 上的同时，亚胺 $\mathrm{N}$ 上的质子迁移到第一个羰基(即丙氨 酸残基的羰基) $\mathrm{C}$ 上形成分子离子复合物( $\mathrm{COM} 2$ 2), $\mathrm{COM} 2$ 的电荷和自由基都在酪氨酸的苯环上，酪氨酸 的 $\mathrm{N}$ 上的 $\mathrm{H}$ 与亚胺的 $\mathrm{N}$ 形成一个较强的氢键 $\left(\left[\mathrm{N}_{2}\right.\right.$ $\left.-\mathrm{H}^{+} \cdots \mathrm{N}_{1} \mathrm{C}\right]$, 氢键键长 1.742 $\AA$ ), 其进一步裂解产 生 $\left[\mathrm{x}_{2}+\mathrm{H}\right]^{{ }^{+}}$和一分子中性的亚胺, 此过程的能垒是 $44.3 \mathrm{kcal} / \mathrm{mol}$.
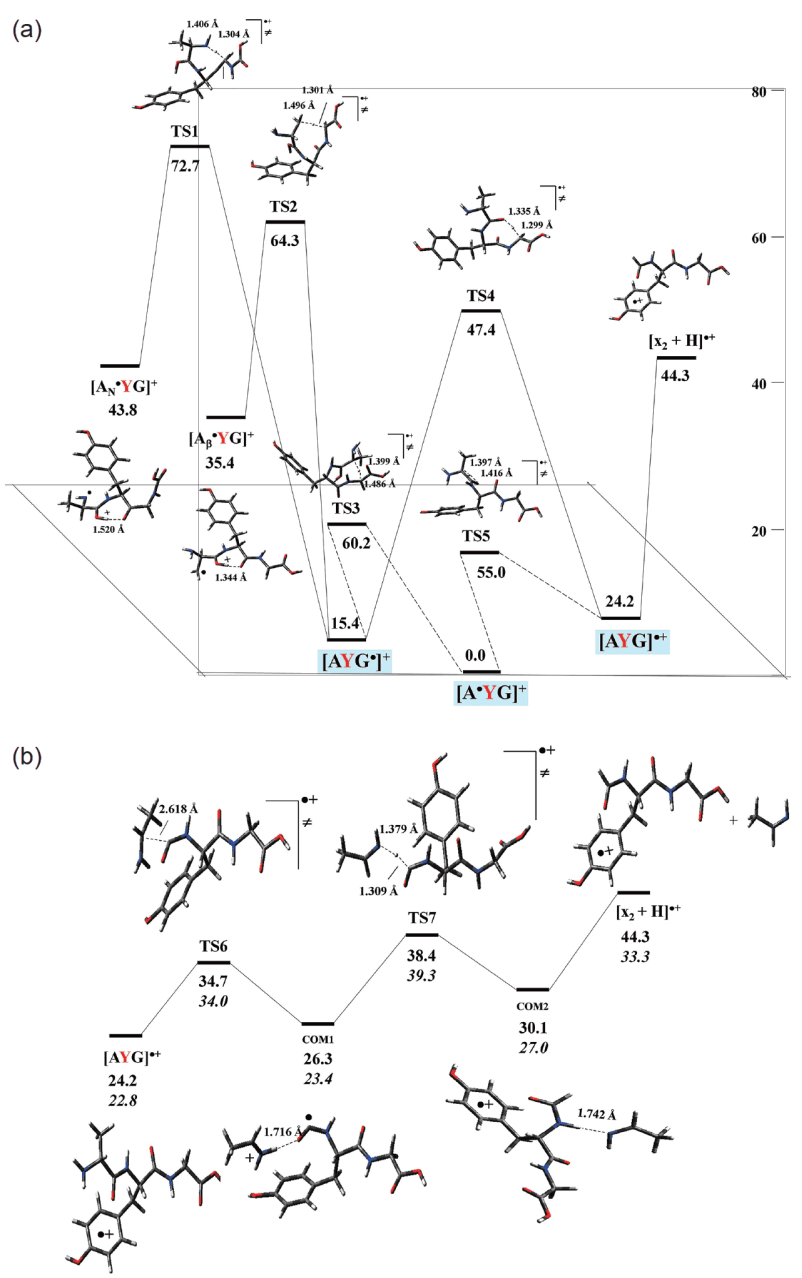

图 7 (a) $[\mathrm{AYG}]^{*+} 、\left[\mathrm{~A}^{*} \mathrm{YG}\right]^{+}$和 $\left[\mathrm{AYG}^{*}\right]^{+}$的气相异构/解离机 理总结图; (b) $[\mathrm{AYG}]^{\circ+}$ 的气相解离机理(上边数字: $0 \mathrm{~K}$ 时的 焓变; 斜体数字: $298 \mathrm{~K}$ 时的自由能). 所有能量 $(\mathrm{kcal} / \mathrm{mol})$ 是相 对于 $\left[\mathrm{A}^{*} \mathrm{YG}\right]^{+}$的相对能量. 所有能量是由 B3LYP/6-31++G(d, p)计算得到(网络版彩图)

Figure 7 (a) Summary of isomerization/dissociation mechanisms for $[\mathrm{AYG}]^{\bullet+},\left[\mathrm{A}^{\bullet} \mathrm{YG}\right]^{+}$and $\left[\mathrm{AYG}^{\bullet}\right]^{+}$; (b) dissociation mechanism of $[\mathrm{AYG}]^{\bullet+}$ (the upper numbers: enthalpies at $0 \mathrm{~K}$; the lower italicized numbers: free energies at $298 \mathrm{~K}$ ). All energies (in $\mathrm{kcal} / \mathrm{mol}$ ) are relative energy to $\left[\mathrm{A}^{\bullet} \mathrm{YG}\right]^{+}$and are calculated at the B3LYP/6-31++G(d,p) levels (color online).

$\left[\mathrm{AYG}^{\bullet}\right]^{+}$可能有三种解离路径(图7(a)): (1) 丙氨酸 $\beta$ 自由基 $\left(\mathrm{A}_{\beta}{ }^{*}\right)$ 中间体路径; (2) 丙氨酸 $\mathrm{N}$ 自由基 $\left(\mathrm{A}_{\mathrm{N}}{ }^{*}\right)$ 中 间体路径; (3) $\left[\mathrm{AYG}^{\bullet}\right]^{+}$异构成 $[\mathrm{AYG}]^{\bullet+}$, 然后经历与 $[\mathrm{AYG}]^{\bullet+}$ 相同的解离过程. 路径(1): $\left[\mathrm{AYG}^{\bullet}\right]^{+}$中丙氨酸 残基的 $\mathrm{C}_{\beta}$ 上的 $\mathrm{H}$ 经过过渡态(TS2 $64.3 \mathrm{kcal} / \mathrm{mol}$ ) 迁移 到甘氨酸残基的 $\mathrm{C}_{\alpha}$ 上, 形成了 $\left[\mathrm{A}_{\beta}{ }^{\circ} \mathrm{YG}\right]^{+}(35.4 \mathrm{kcal} /$ $\mathrm{mol}$ ), 其自由基和电荷分别在丙氨酸残基的 $\mathrm{C}_{\beta}$ 上和羰 基 $\mathrm{O}$ 上，第一个羰基(即丙氨酸残基的羰基) $\mathrm{O}$ 上的 $\mathrm{H}$ 与 
第二个羰基(即酪氨酸残基的羰基) $\mathrm{O}$ 形成一个很强的 氢键 $\left(\left[\mathrm{CO}_{1}-\mathrm{H}^{+} \cdots \mathrm{O}_{2} \mathrm{C}\right]\right.$, 氢键键长 $\left.1.344 \AA\right)$, 此路径的 能垒为 $64.3 \mathrm{kcal} / \mathrm{mol}$; 路径(2): $\left[\mathrm{AYG}^{\circ}\right]^{+}$中丙氨酸残基 的氨基 $\mathrm{N}$ 上的 $\mathrm{H}$ 经过过渡态 $(\mathrm{TS} 172.7 \mathrm{kcal} / \mathrm{mol}$ )迁移到 甘氨酸残基的 $\mathrm{C}_{\alpha}$ 上，形成了 $\left[\mathrm{A}_{\mathrm{N}}{ }^{\circ} \mathrm{YG}\right]^{+}(43.8 \mathrm{kcal} / \mathrm{mol})$, 其自由基和电荷分别在丙氨酸残基的氨基 $\mathrm{N}$ 上和羰基 $\mathrm{O}$ 上，第一个羰基(即丙氨酸残基的羰基) $\mathrm{O}$ 上的 $\mathrm{H}$ 与第 二个羰基(即酪氨酸残基的羰基) $\mathrm{O}$ 形成一个强的氢键 $\left(\left[\mathrm{CO}_{1}-\mathrm{H}^{+} \cdots \mathrm{O}_{2} \mathrm{C}\right]\right.$, 氢键键长 $\left.1.520 \AA\right)$, 此路径的能垒 为 $72.7 \mathrm{kcal} / \mathrm{mol}$; 路径(3): $\left[\mathrm{AYG}^{\circ}\right]^{+}$异构为 $[\mathrm{AYG}]^{\circ+}$ 的过 程，能垒为 $47.4 \mathrm{kcal} / \mathrm{mol}$. 比较以上三种路径的能垒可 知, $\left[\mathrm{AYG}^{\bullet}\right]^{+}$先异构为 $[\mathrm{AYG}]^{\bullet+}$, 然后再经历 $[\mathrm{AYG}]^{\bullet+}$ 解 离并产生 $\left[\mathrm{x}_{2}+\mathrm{H}\right]^{-+}$的过程为最低能量反应路径, 这也解 释了 $\left[\mathrm{AYG}^{\bullet}\right]^{+}$和 $[\mathrm{AYG}]^{\bullet+} \mathrm{CID}$ 谱图相同的原因所在.

\subsubsection{AYG和GYG自由基离子不同气相解离行为 的可能原因}

很明显, [GYG $\left.^{\bullet}\right]^{+}$和 $[\mathrm{GYG}]^{\bullet+}$ 的 CID谱图是不完全 相同的, 说明两个离子可能发生部分异构, 而 $\left[\mathrm{AYG}^{\circ}\right]^{+}$ 是可以完全异构为 $[\mathrm{AYG}]^{\bullet+}$ 进而产生 $\left[\mathrm{x}_{2}+\mathrm{H}\right]^{\bullet+}$ 产物离 子. 因此, 本部分仅重点讨论 $[G Y G]^{\bullet+}$ 和 $[A Y G]^{\bullet+}$ 的气相 解离反应特征. 图8分别给出了 $[\mathrm{AYG}]^{\bullet+}$ 和 $[\mathrm{GYG}]^{\bullet+} \mathrm{N}$ 端 $\mathrm{C}_{\alpha}-\mathrm{C}$ 键断裂过渡态. $[\mathrm{AYG}]^{\circ+} \mathrm{N}$ 端 $\mathrm{C}_{\alpha}-\mathrm{C}$ 键断裂过渡态 (TS6)能量为 $34.7 \mathrm{kcal} / \mathrm{mol}$, 而 $[\mathrm{GYG}]^{++} \mathrm{N}$ 端 $\mathrm{C}_{\alpha}-\mathrm{C}$ 键断 裂过渡态(TS8)能量是 $41.0 \mathrm{kcal} / \mathrm{mol}$ ，二者相差 $6.3 \mathrm{kcal} /$ $\mathrm{mol}$, 因此, $[\mathrm{AYG}]^{\bullet+}$ 是通过断裂 $\mathrm{N}$ 端 $\mathrm{C}_{\alpha}-\mathrm{C}$ 键产生 $\left[\mathrm{x}_{2}\right.$ $+\mathrm{H}]^{\bullet+}$ 碎片离子, 而 $[\mathrm{GYG}]^{\bullet+}$ 不能产生 $\left[\mathrm{x}_{2}+\mathrm{H}\right]^{\bullet+}$.

\section{4 结论}

本文采用ESI-MS/MS方法结合DFT量化计算的方 法，得到了具有不同位点AYG自由基离子([AYG $]^{\bullet+}$ 、 $\left[\mathrm{A}^{\bullet} \mathrm{YG}\right]^{+}$和 $\left.\left[\mathrm{AYG}^{\bullet}\right]^{+}\right)$的气相稳定性及其气相异构/解离 反应机理. 通过对比AYG不同位点自由基离子的CID 谱图得知, $[\mathrm{AYG}]^{\bullet+}$ 和 $\left[\mathrm{AYG}^{\circ}\right]^{+}$的解离路径基本相同, 二 者的主要裂解产物均为 $\left[\mathrm{x}_{2}+\mathrm{H}\right]^{\circ+}$ 离子, 说明二者在解离 之前已完全异构; $\left[\mathrm{A}^{\bullet} \mathrm{YG}\right]^{+}$和 $\left[\mathrm{G}^{\bullet} \mathrm{YG}\right]^{+}$的解离路径相同, (a)

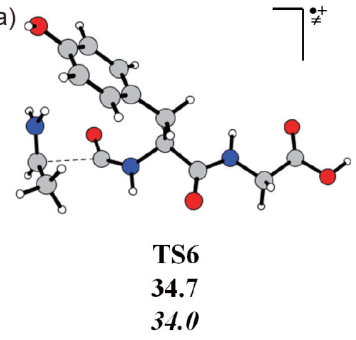

(b)

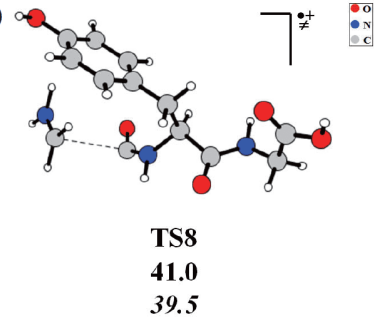

图 8 [AYG $^{\circ+}$ (a) 和 $[\mathrm{GYG}]^{\circ+}$ (b)中 $\mathrm{N}^{-}$端 $\mathrm{C}_{\alpha}-\mathrm{C}$ 键断裂的过渡态 $(\mathrm{C}=$ 灰色; $\mathrm{O}=$ 红色; $\mathrm{N}=$ 蓝色; $\mathrm{H}=$ 白色; 上边数字: $0 \mathrm{~K}$ 时的焓 变; 斜体数字: $298 \mathrm{~K}$ 时的自由能). 所有能量 $(\mathrm{kcal} / \mathrm{mol})$ 是相 对于 $\left[\mathrm{A}^{*} Y G\right]^{+}$的相对能量. 所有能量是由 $\mathrm{B} 3 \mathrm{LYP} / 6-31++\mathrm{G}(\mathrm{d}$, p)计算得到(网络版彩图)

Figure 8 The transition states of $\mathrm{N}$-terminal $\mathrm{C}_{\alpha}-\mathrm{C}$ bond cleavage for $[\mathrm{AYG}]^{++}$(a) and $[\mathrm{GYG}]^{++}$(b). All energies (in $\mathrm{kcal} / \mathrm{mol}$ ) are relative energy to $\left[\mathrm{A}^{*} \mathrm{YG}\right]^{+}$and are calculated at the $\mathrm{B} 3 \mathrm{LYP} / 6-31++\mathrm{G}(\mathrm{d}, \mathrm{p})$ levels (color online).

二者均断裂酰胺 $\mathrm{C}-\mathrm{N}$ 键, 产生 $\left[\mathrm{b}_{2}-\mathrm{H}\right]^{\bullet+}$ 碎片离子, 说明 $\left[\mathrm{A}^{\bullet} \mathrm{YG}\right]^{+}$不能异构为 $[\mathrm{AYG}]^{\bullet+}$ 和 $\left[\mathrm{AYG}^{\bullet}\right]^{+}$. 此结果得到量 化计算的证实: (1) $\mathrm{AYG}$ 三种自由基离子的异构/解离 能垒分别是: $\left[\mathrm{AYG}^{\circ}\right]^{+} \rightarrow[\mathrm{AYG}]^{\circ+}$ 的异构能垒 $(47.4 \mathrm{kcal} /$ $\mathrm{mol})$ 低于 $\left[\mathrm{AYG}^{\circ}\right]^{+}$的解离能垒 $(72.7 \mathrm{kcal} / \mathrm{mol})$, 但高于 $[\mathrm{AYG}]^{\circ+}$ 的解离能垒 $(44.3 \mathrm{kcal} / \mathrm{mol})$. 所以, $\left[\mathrm{AYG}^{\circ}\right]^{+}$的 气相裂解反应要经历两个过程, 即 $\left[\mathrm{AYG}^{\circ}\right]^{+}$先异构为 $[\mathrm{AYG}]^{\bullet+}$, 再发生与 $[\mathrm{AYG}]^{\bullet+}$ 相同的解离反应, 断裂 $\mathrm{N}$ 端 $\mathrm{C}_{\alpha}-\mathrm{C}$ 键产生 $\left[\mathrm{x}_{2}+\mathrm{H}\right]^{-+}$碎片离子. (2) $\left[\mathrm{A}^{\bullet} \mathrm{YG}\right]^{+}$不能异构 为 $[\mathrm{AYG}]^{\bullet+}$ 和 $\left[\mathrm{AYG}^{\bullet}\right]^{+}$, 因为 $\left[\mathrm{A}^{\bullet} \mathrm{YG}\right]^{+}$的异构能垒 $\left(\left[\mathrm{A}^{\bullet}\right.\right.$ $\left.\mathrm{YG}]^{+} \rightarrow[\mathrm{AYG}]^{\bullet+}, \quad 55.0 \mathrm{kcal} / \mathrm{mol}\right) ;\left[\mathrm{A}^{\circ} \mathrm{YG}\right]^{+} \rightarrow\left[\mathrm{AYG}^{\bullet}\right]^{+}$, $60.2 \mathrm{kcal} / \mathrm{mol})$ 要比其解离能垒 $\left(\left[\mathrm{A}^{\circ} \mathrm{YG}\right]^{+} \rightarrow\left[\mathrm{b}_{2}-\mathrm{H}\right]^{\bullet+}\right.$, $33.8 \mathrm{kcal} / \mathrm{mol}$ )高很多. 所以, $\left[\mathrm{A}^{\circ} \mathrm{YG}\right]^{+}$将直接发生电荷 诱导的断裂第二个酰胺键 (从 $\mathrm{N}$ 端氨基酸残基数起)反 应而产生 $\left[\mathrm{b}_{2}-\mathrm{H}\right]^{\bullet+}$ 碎片离子. 通过对比AYG和 GYG两 个系列自由基离子的CID谱图可知，GYG与AYG自由 基离子具有截然不同的气相解离特征. $\left[\mathrm{GYG}^{\circ}{ }^{\bullet+}\right.$ 和 $\left[\mathrm{GYG}^{*}\right]^{+}$的气相裂解产物不完全相同，说明 $[\mathrm{GYG}]^{\bullet+}$ 和 $\left[\mathrm{GYG}^{\bullet}\right]^{+}$在解离前可能发生部分异构. $[\mathrm{AYG}]^{\bullet+}$ 和 $[\mathrm{GYG}]^{\bullet+}$ 的气相碎裂产物不同, 前者断裂 $\mathrm{N}$ 端 $\mathrm{C}_{\alpha}-\mathrm{C}$ 键 产生 $\left[\mathrm{x}_{2}+\mathrm{H}\right]^{\bullet+}$ 碎片离子，而后者断裂第二个 $\mathrm{N}-\mathrm{C}_{\alpha}$ (从 $\mathrm{N}$ 端氨基酸残基数起)键产生 $\left[\mathrm{z}_{2}-\mathrm{H}\right]^{\bullet+}$ 碎片离子. 


\section{补充材料}

本文的补充材料见网络版http://chemen.scichina.com. 补充材料为作者提供的原始数据, 作者对其学术质量和内容负责.

\section{参考文献}

1 Radi R. Acc Chem Res, 2013, 46: 550-559

2 Opazo C, Huang X, Cherny RA, Moir RD, Roher AE, White AR, Cappai R, Masters CL, Tanzi RE, Inestrosa NC, Bush AI. J Biol Chem, 2002, 277: 40302-40308

3 Lai CK, Tang WK, Siu C-, Chu IK. Chem Eur J, 2020, 26: 331-335

4 Lambeth TR, Riggs DL, Talbert LE, Tang J, Coburn E, Kang AS, Noll J, Augello C, Ford BD, Julian RR. ACS Cent Sci, 2019, 5: 1387-1395

5 Stubbe JA. Chem Commun, 2003, 9: 2511-2513

6 Hawkins CL, Davies MJ. Biochim Biophys Acta, 2001, 1504: 196-219

7 Mu X, Song T, Siu CK, Chu IK. Chem Rec, 2018, 18: 20-44

8 Mu X, Tang WK, Dong N, Li M, Siu CK, Chu IK. Int J Mass Spectrometry, 2019, 435: 333-341

9 Mu X, Lau JKC, Lai CK, Siu KWM, Hopkinson AC, Chu IK. Phys Chem Chem Phys, 2017, 19: 16923-16933

10 Ng DCM, Song T, Siu SO, Siu CK, Laskin J, Chu IK. J Phys Chem B, 2010, 114: 2270-2280

11 Lai CK, Mu X, Hao Q, Hopkinson AC, Chu IK. Phys Chem Chem Phys, 2014, 16: 24235-24243

12 Piatkivskyi A, Lau JKC, Berden G, Oomens J, Hopkinson AC, Siu KM, Ryzhov V. Eur J Mass Spectrom (Chichester), 2019, 25: 112-121

13 Biemann K, McCloskey JA. J Am Chem Soc, 1962, 84: 3192-3193

14 Weinkauf R, Schanen P, Metsala A, Schlag EW, Bürgle M, Kessler H. J Phys Chem, 1996, 100: 18567-18585

15 Zubarev RA, Horn DM, Fridriksson EK, Kelleher NL, Kruger NA, Lewis MA, Carpenter BK, McLafferty FW. Anal Chem, 2000, 72: 563-573

16 Zubarev RA. Curr Opin Biotech, 2004, 15: 12-16

17 Straus RN, Jockusch RA. J Am Soc Mass Spectrom, 2017, 28: 358-369

18 Syka JEP, Coon JJ, Schroeder MJ, Shabanowitz J, Hunt DF. Proc Natl Acad Sci USA, 2004, 101: 9528-9533

19 Han H, Xia Y, McLuckey SA. J Proteome Res, 2007, 6: 3062-3069

20 Kempkes LJM, Martens J, Berden G, Oomens J. J Phys Chem Lett, 2018, 9: 6404-6411

21 Barlow CK, McFadyen WD, O'Hair RAJ. J Am Chem Soc, 2005, 127: 6109-6115

22 Wee S, Mortimer A, Moran D, Wright A, Barlow CK, O'Hair RAJ, Radom L, Easton CJ. Chem Commun, 2006, 40: 4233-4235

23 Hao G, Gross SS. J Am Soc Mass Spectrom, 2006, 17: 1725-1730

Ryzhov V, Lam AKY, O’Hair RAJ. J Am Soc Mass Spectrom, 2009, 20: 985-995

Knudsen ER, Julian RR. Int J Mass Spectrometry, 2010, 294: 83-87

Talbert LE, Zhang X, Hendricks N, Alizadeh A, Julian RR. Int J Mass Spectrometry, 2019, 441: 25-31

Hodyss R, Cox HA, Beauchamp JL. J Am Chem Soc, 2005, 127: 12436-12437

Lee J, Kim Y, Kim WY, Oh HB. Phys Chem Chem Phys, 2020, 22: 5057-5069

Bagheri-Majdi E, Ke Y, Orlova G, Chu IK, Hopkinson AC, Siu KWM. J Phys Chem B, 2004, 108: 11170-11181

Lau JKC, Lo S, Zhao J, Siu KWM, Hopkinson AC. J Am Soc Mass Spectrom, 2013, 24: 543-553

Chu IK, Zhao J, Xu M, Siu SO, Hopkinson AC, Siu KWM. J Am Chem Soc, 2008, 130: 7862-7872

Siu C, Ke Y, Orlova G, Hopkinson A, Michaelsiu K. J Am Soc Mass Spectrometry, 2008, 19: 1799-1807

Mu X, Song T, Xu M, Lai CK, Siu CK, Laskin J, Chu IK. J Phys Chem B, 2014, 118: 4273-4281

Henke W, Kremer S, Reinen D. Inorg Chem, 1983, 22: 2858-2863

Chan WC, White PD. Fmoc Solid Phase Peptide Synthesis: A Practical Approach. Oxford: IRL Press, 2000

Lee C, Yang W, Parr RG. Phys Rev B, 1988, 37: 785-789

Zhao Y, Truhlar DG. J Chem Phys, 2006, 125: 194101

Gonzalez C, Schlegel HB. J Chem Phys, 1989, 90: 2154-2161

Harrison AG. Mass Spectrom Rev, 1997, 16: 201-217 


\title{
Formation, isomerization, and dissociation of tyrosine-containing tripeptide radical cations
}

\author{
Shifang Lu, Jie Cao*, Heyuan Jia, Shuoqi Sun, Shilv Chen ${ }^{*}$ \\ Key Laboratory of Cluster Science (Beijing Institute of Technology), Ministry of Education, School of Chemistry and Chemical Engineering, Beijing \\ Institute of Technology, Beijing 100081, China \\ *Corresponding authors (email: jcao@bit.edu.cn; shlchen@bit.edu.cn)
}

\begin{abstract}
Two series of tripeptide radical cations ([AYG $]^{\bullet+},\left[\mathrm{AYG}^{\bullet}\right]^{+} ;[\mathrm{GYG}]^{\bullet+},\left[\mathrm{G}^{\bullet} \mathrm{YG}^{+}\right.$and $\left[\mathrm{GYG}^{\bullet}\right]^{+}$) were successfully prepared via multistage collision-induced dissociation (CID) of a ternary complex of copper-ligandtripeptide $[\mathrm{Cu}(\mathrm{L}) \text { Peptide }]^{2+}$ ( $\mathrm{L}=4^{\prime}$-chloro-2,2':6',2"terpyridine (4Cl-tpy); Peptide=alanyl-tyrosyl-glycine (AYG) or glycyl-tyrosyl-glycine (GYG) tripeptide). The gas-phase isomerization and dissociation mechanism of isomeric AYG radical ions, and the different dissociation behaviors between AYG and GYG radical ions, have been obtained by observing their gas-phase dissociation reactions combined with density functional theory (DFT) calculation. Studies have revealed that: (1) $\left[\mathrm{AYG}^{\circ}\right]^{+}$and $[\mathrm{AYG}]^{++}$produced almost identical CID spectra (their main product ions are $\left[\mathrm{x}_{2}\right.$ $+\mathrm{H}]^{++}$ions), suggesting that interconversion occurs prior to dissociation. (2) The dissociation paths of $\left[\mathrm{A}^{\bullet} \mathrm{YG}^{+}\right.$and $\left[\mathrm{G}^{\circ} \mathrm{YG}\right]^{+}$are the same (both of which produces $\left[\mathrm{b}_{2}-\mathrm{H}\right]^{\bullet+}$ fragment ions by cleavage of amide $\mathrm{C}-\mathrm{N}$ bond, indicating that $\left[\mathrm{A}^{\bullet} \mathrm{YG}\right]^{+}$cannot isomerize to $\left[\mathrm{AYG}^{\bullet}\right]^{+}$and $[\mathrm{AYG}]^{++}$. DFT calculation gives the gas-phase stability order of these three peptide radical ions $\left(\left[\mathrm{A}^{\bullet} \mathrm{YG}\right]^{+}>[\mathrm{AYG}]^{\bullet}>[\mathrm{AYG}]^{\bullet+}\right)$ and their isomerization/dissociation energy barriers. Isomerization energy barrier $(47.4 \mathrm{kcal} / \mathrm{mol})$ of $\left[\mathrm{AYG}^{\circ}\right]^{+} \rightarrow[\mathrm{AYG}]^{\circ+}$ is lower than dissociation energy barrier $(72.7 \mathrm{kcal} / \mathrm{mol})$ of $\left[\mathrm{AYG}^{\circ}\right]^{+}$, but higher than that $(44.3 \mathrm{kcal} / \mathrm{mol})$ of $[\mathrm{AYG}]^{\circ+}$, thereby the gas-phase dissociation mechanism of $\left[\mathrm{AYG}^{\circ}\right]^{+}$ undergoes a two-step reaction: the first step is the isomerization process of $\left[\mathrm{AYG}^{\bullet}\right]^{+} \rightarrow[\mathrm{AYG}]^{{ }^{+}}$, and the second step is the dissociation reaction of $[\mathrm{AYG}]^{\circ+} \rightarrow\left[\mathrm{x}_{2}+\mathrm{H}\right]^{\circ+}$, which produces $\left[\mathrm{x}_{2}+\mathrm{H}\right]^{\circ+}$ fragment ions by cleavage of $\mathrm{N}$-terminal $\mathrm{C}_{\alpha}-\mathrm{C}$ bond in $[\mathrm{AYG}]^{\bullet+}$. (4) The gas-phase dissociation characteristics of $[\mathrm{GYG}]^{\circ+}$ and $[\mathrm{AYG}]^{\circ+}$ are dramatically different. $[\mathrm{GYG}]^{\bullet+}$ mainly produces $\left[\mathrm{z}_{2}-\mathrm{H}\right]^{\bullet+}$ by cleavage of the second $\mathrm{N}-\mathrm{C}_{\alpha}$ bond (counting from the $\mathrm{N}$-terminal amino acid residue).
\end{abstract}

Keywords: electrospray ionization-mass spectrometry (ESI-MS), density functional theory (DFT), tripeptide radical ions, gas-phase isomerization and dissociation

doi: $10.1360 /$ SSC-2020-0080 